\title{
Do Isolamento Social ao Crescimento Pessoal: Reflexões Sobre o Impacto Psicossocial da Pandemia
}

\section{From Social Isolation to Personal Growth: Reflections About the Psychosocial Impact of the Pandemic}

Marta Gonçalves ${ }^{1}$, Magda A. Oliveira², Ana P. Pinheiro ${ }^{3}$

"Nunca devemos esquecer que podemos encontrar sentido na vida mesmo quando confrontados com uma situação desesperançada ou com um destino que não pode ser alterado.

O que importa é dar testemunho do potencial humano, capaz de transformar uma tragédia pessoal num triunfo, um obstáculo numa realização pessoal.

Quando já não somos capazes de modificar a situação, somos desafiados a mudarmo-nos a nós mesmos".

VIKTOR FRANKL (1957)

\section{INTRODUÇÃO}

Esta é uma reflexão que combina o olhar integrado da Psiquiatria, da Psicologia Clínica e da Neuropsico- logia sobre o impacto psicossocial da pandemia por COVID-19. As secções seguintes abordam algumas das dimensões da existência humana mais afetadas pela pandemia, através de um diálogo entre duas perspetivas: o existencialismo e a ciência.

\section{PERDA DE LIBERDADE, CONTROLO E PREVISIBILIDADE}

"Não posso sair, nem sequer para trabalhar; não sei como irá ser e até quando. E o pior é que também ninguém me sabe dizer. Sinto-me perdida, a perder o controlo de tudo que tinha até agora, e não consigo imaginar o que ainda aí vem. Vou ter trabalho? Vou conseguir alimentar os meus filhos? Vou perder algum dos meus familiares? O que está a acontecer ao mundo, às nossas vidas e a tudo que dávamos como

\footnotetext{
1. Psiquiatra; Serviço de Psiquiatria / Psicologia Clínica do Hospital CUF Porto, Porto, Portugal. 2. Psicóloga Clínica e da Saúde; Serviço de Psiquiatria / Psicologia Clínica do Hospital CUF Porto, Porto, Portugal. 3. Neuropsicóloga; Serviço de Psiquiatria / Psicologia Clínica do Hospital CUF Porto, Porto, Portugal; Faculdade de Psicologia, Universidade de Lisboa, Lisboa, Portugal. 
certo? Estamos ao sabor de um vírus que desconhecemos e que nos tirou a liberdade. Afinal não controlamos mesmo nada! Tudo é efémero..."

O ser humano tem aversão à incerteza e à imprevisibilidade. Um dos modelos influentes em neurociências (predictive coding ${ }^{1}$ ) postula que, a cada instante, o ser humano procura minimizar erros de predição: automaticamente, predizemos o que vai acontecer de seguida (e.g., o esboçar de um sorriso é preditor de uma gargalhada). Contudo, quando tal não acontece, o esforço cognitivo aumenta. Perante a incerteza do futuro (e.g., quando poderei voltar a ver os meus entes queridos?; quando poderei sair de casa?), o ser humano é confrontado com a necessidade de adaptação.

De repente, o anúncio de uma pandemia em pleno século XXI, para a qual era impossível estarmos preparados, trouxe consigo o choque e o medo: os projetos e planos pessoais e profissionais a curto e médio-prazo foram abalados, o quotidiano foi radicalmente alterado e a noção de "normalidade" foi questionada. $\bigcirc$ mundo como o conhecíamos passou a ser um lugar diferente e sombrio e, o futuro passou a ser ainda mais enigmático. Considerando o impacto global da presente pandemia, a incerteza que lhe está associada poderá ter implicações diretas para a saúde mental a nível global. ${ }^{2-3}$ Estudos recentes apontam para os efeitos a curto-prazo do coronavírus na saúde mental. Por exemplo, um aumento da prevalência de sintomas como depressão e ansiedade foi reportado numa meta-análise recente. ${ }^{4}$ Considerando a evidência de que dispomos com base em epidemias passadas (e.g., SARS, MERS), é muito provável que estes efeitos se mantenham a longo-prazo, destacando a importância de intervenções precoces em saúde mental, bem como de estudos longitudinais. ${ }^{2}$

\section{AMEAÇA E MEDO}

"Tenho medo: medo de ficar doente, medo que alguém próximo adoeça, medo de perder os que mais gosto, medo de não conseguir sobreviver depois disto... Não estou a conseguir avançar, fico presa nas notícias quase de hora a hora, paralisada no tempo. O tempo parou e tudo ficou suspenso. Aguardo boas notícias, que não acontecem. Sinto que o mundo parou e com ele todos nós. O nosso tempo já não é o mesmo tempo."

A resposta de medo representa um mecanismo adaptativo que é fundamental para a sobrevivência humana, envolvendo um conjunto de processos neurobiológicos que nos preparam para responder a acontecimentos potencialmente ameaçadores. No contexto de uma pandemia, em que a ameaça à saúde, bem-estar e vida se torna premente, o medo - medo pandémico - constitui uma resposta esperada e adaptativa, estando na base de comportamentos que evitam o risco de contaminação e aumentam a probabilidade de sobrevivência. ${ }^{5}$ Contudo, quando crónica e desproporcionada, esta resposta passa a ser desadaptativa. Uma resposta de medo exagerada poderá levar a evitamento excessivo, de tal modo que a pessoa 'paralisa', não conseguindo tomar decisões racionais e deixando de ser capaz de realizar atividades do dia-a-dia de forma eficaz.

Nos últimos meses, a experiência de medo de ser infetado ou de infetar terceiros, sobretudo entes queridos, passou a ser comum na população global, não só em pessoas infetadas. Assistimos ainda, a relatos de suicídio de profissionais de saúde que não conseguiram viver com o sentimento de culpa de terem infetado outras pessoas, as quais acabaram por falecer. Por outro lado, o medo das consequências económicas da COVID-19, nomeadamente a recessão económica, desemprego e dívida, poderá ter efeitos ainda mais nefastos para algumas pessoas. Os efeitos do isolamento social e do medo poderão ainda ser mais adversos em pessoas com vulnerabilidades prévias. Por exemplo, pessoas com sintomas psicopatológicos prévios à pandemia poderão ser ainda mais vulneráveis aos efeitos negativos do isolamento social. 4

\section{DINÂMICAS SOCIAIS}

"Em casa, com o marido e os filhos, digamos que de certa forma em retiro familiar, foi um tempo único... Dividiamos as tarefas domésticas, ficávamos horas infindas à mesa a conversar, víamos filmes que aguardavam há muito e com tempo para os comentar. Até tivemos tempo para nos enamorar. Ao mesmo tempo, alguns dos nossos amigos, discutiam por tudo e por nada, acusavam-se mutuamente, ora de falta de compaixão para com quem sofria, ou de falta de disponibilidade para ajudar, ou por outro lado, por preocupações doentias com o vírus, hipocondria desmedida e incapacidade para se organizar. Podemos dizer que, de certa forma, confinamos com o melhor e o pior de nós próprios, as diferenças e as semelhanças exacerbam-se, reencontrando-nos ou afastando-nos, por vezes definitivamente".

As relações e dinâmicas interpessoais são moldadas pelas emoções positivas ou negativas expressas num determinado momento temporal e contexto. No caso extremo do isolamento social num contexto pandémico, estas dinâmicas são inevitavelmente alteradas, implicando novas formas de contacto interpessoal.

O clima de medo associado a uma pandemia pode, em especial, gerar a sensação de terror de se perder entes 
queridos e amigos, aliada à saudade e tristeza de não se poder estar em contacto com as pessoas que tanto significado trazem ao mundo pessoal de cada um. Num mundo digital, o isolamento social pode ser minimizado pelo aumento de contactos através de meios digitais (e.g., WhatsApp, Skype, Zoom), que, em muitos casos, se intensificaram por comparação com o período pré-pandemia. Nesse sentido, apesar da distância física, algumas relações podem ser fortalecidas, aumentando-se a cumplicidade e proximidade emocionais, mesmo na ausência de contacto físico. Simultaneamente, tal poderá ter resultado numa melhoria de competências no uso de tecnologias, por exemplo em pessoas mais velhas que passaram a depender destes meios para se sentirem mais próximas dos seus entes queridos.

Contudo, num outro cenário, a proximidade física entre pessoas que coabitam poderá ter aumentado, nomeadamente o tempo despendido com filhos, companheiros, pais ou irmãos. Para alguns, esta situação pode ter levado ao estreitamento de vínculos e à possibilidade de maior tempo de qualidade (e.g., atividades de lazer; tempo passado em refeições conjuntas). Todavia, para outros, esta situação poderá ter exacerbado conflitos familiares latentes, potencialmente agravados por desequilíbrios financeiros, desemprego ou medo de perder o emprego. Alguns especialistas alertam para um "tsunami" psicológico eminente, quer através dos efeitos psicopatológicos do isolamento social, quer através das tentativas extraordinárias de conter esses efeitos. ${ }^{4}$ Apesar de ainda ser cedo para se estimar os efeitos do coronavírus no reajustamento das dinâmicas interpessoais, é de esperar uma alteração profunda no modo como nos relacionamos socialmente (nos próximos meses e, eventualmente, anos), bem como no modo como conceptualizamos as relações sociais. Por exemplo, é provável que as nossas rotinas de cumprimentar conhecidos e desconhecidos se alterem drasticamente, minimizando-se o contacto próximo.

\section{LUTO}

O último adeus a uma vida!

A despedida mesmo que espiritual, não deixa de ser o último adeus a uma vida: o toque nas mãos, a festa na face e um último olhar. Depois disto, só restará mesmo a saudade e as memórias do passado. O presente e futuro dessa presença desparecerão para sempre.

A possibilidade da derradeira vivência deste adeus foi-nos roubada na pandemia! Entrou doente no hospital e saiu com o caixão fechado. E eu, e nós, ficamos sem direito à despedida, à última troca de palavras, mesmo que em silên- cio! Como elaborar um processo de luto assim? Negando-o, adiando-o e interiorizando-o talvez de uma forma penosa e esplanada no tempo. O processo ficou incompleto. E nós incompletos ficamos.

Mais tarde, quando ninguém o esperava, angustiamos, deprimimos e procurando ajuda ou não, porque não percebemos o porquê desta tristeza, desta dor, tantas vezes corporalizada. Está tudo aparentemente bem, as análises excelentes, o exame físico perfeito, apenas a postura e o olhar denotam um vazio sem fim. Sim, faltou a tal despedida".

A morte e tudo o que envolve o morrer coloca-nos perante as maiores incógnitas da vida, perante os maiores medos e a maior das dores: a perda daqueles que tanto amamos. É um território de fantasias, de crenças, necessidades e reações singulares para as quais procuramos desesperadamente respostas, ou inversamente, escapes que evitem tudo o que evoca. Numa pandemia tudo isto fica exacerbado: a morte está mais presente na ameaça de infeção de alguém amado (pior se formos quem transmite), na impossibilidade de uma cura, na avalanche de notícias que anunciam uma mortalidade exponencial que paira, sufoca e aguça a vigilância. Ainda em todos os outros: nos que prestam cuidados de saúde, nos que pela existência de uma condição clínica se tornam mais vulneráveis, e nos tantos mais já num processo de final de vida que a pandemia não interrompeu. Como todas estas mortes se podem tornar tão duras, ainda mais dolorosas e cruéis no momento em que se vive.

Ninguém deseja uma morte ou doença progressiva. Mas, quando se ama, quer-se cuidar a cada instante, dar amor, conforto e dignidade. Estar presente, ser parte, dizer "estou aqui, não saio de ao pé de ti, farei tudo o que precisares". Foi tudo isto e muito mais que a COVID-19 usurpou. Pelas restrições impostas pelas instituições hospitalares e normas de saúde pública muito deixou de ser possível: a prestação de cuidados de proximidade na presença e no toque (em contexto hospitalar ou domiciliário); as tarefas de preparação para a perda e de antecipação do luto (as últimas palavras frente a frente, o último abraço, o pedido de desculpa ou obrigado guardado para este momento, um pedido para quem fica e tanto mais); a presença física que segura a mão no momento da morte; a despedida suportada na dor de quem está a viver o mesmo; os rituais de despedidas, exéquias e enterro; as homenagens e formas simbólicas de dizer adeus. ${ }^{5-7}$ A impossibilidade de um último olhar num quarto de hospital, a ausência daqueles com quem se partilhou a vida na despedida, a imposição de uma cerimónia fúnebre muitas vezes distinta do desejado... Tudo parece tornar a morte mais difícil e a passagem pela vida mais insignificante. Tudo deixa um vazio ainda 
maior e uma sensação de percurso interrompido, inacabado por parte dos que ficam. Seria ilógico pensar que estes seriam lutos iguais aos outros. Não são. Existem inevitavelmente implicações nas respostas fisiológicas, emocionais, cognitivas, comportamentais, espirituais e até culturais inerentes ao processo de perda. Apresentam-se como um risco acrescido para a não resolução saudável destes processos de luto, e até mesmo para a emergência de processos de luto complicados, ${ }^{6-7}$ quer pela devassa de um momento que mesmo na dor deveria ser especial, quer pela ilusão da facilitação do processo junto daqueles que sempre buscaram evitar o confronto com a morte e sua irreversibilidade. Para ambos trará desafios acrescidos no caminho a percorrer.

\section{O TOQUE}

"Preciso de tocar, abraçar e sentir o cheirinho do meu neto", dizia Maria ao fazer os seus 70 anos. "Eu sei que há riscos, riscos de adoecer, riscos até de morrer, mas não quero viver assim. Não me privem desse abraço apertado que me enche a alma, que me dá alento para viver o tempo que me resta. Já vos fiz a vontade muitas vezes, fui aos médicos a que me levaram, fiz as análises que quiseram, fiquei em casa isolada durante a quarentena, mas agora chega, chega. Deixem-me decidir como quero viver. O meu tempo e o vosso tempo são diferentes. E do meu tempo só eu sei".

Temos assim tanto direito sobre eles, sobre os nossos queridos idosos, quando lúcidos e capazes? Tudo em prol da sua saúde, para os protegermos - dizemos nós. Mas que saúde é esta de que falamos? Será que estamos mesmo a protegê-los? Ou simplesmente a fazer aquilo com que lidamos meIhor, independentemente das suas escolhas e do seu sentir? Até quando queremos ser os tais?

Quantos de nós já observamos o efeito calmante e securizante de um toque, de uma carícia ou aconchego num bebé agitado, numa criança assustada e até num adulto descontrolado? Quantos de nós já paramos para tentar compreender como o amor, a bondade e a afetividade recíproca exercem sobre nós este efeito? E quantos de nós já tomamos consciência de que as manifestações afetivas são uma poderosa terapêutica na regulação emocional do sofrimento, do stresse e das necessidades de segurança e bem-estar?

As abordagens evolucionistas e desenvolvimentistas dão nota de como o cérebro humano, em particular as estruturas pré-frontais, vem inaptamente programado para orientar cada um de nós para relações de proximidade e segurança, tão importantes desde o início da vida: na preservação da adaptação, na sobrevivência e na transcendência humana. ${ }^{8}$ É neste contexto biológico, social e familiar que se estabelecem os principais vínculos e laços afetivos desde o início da vida. São estas as raízes de um sistema de afiliação que, através das suas vias químicas, liberta endorfinas, opioides e oxitocina, responsáveis por emoções ligadas à acalmia física e psíquica, ao descanso e relaxamento, ao apaziguamento e proteção, à conectividade connosco e com o outro, e até à espiritualidade e busca de novos sentidos para as experiências. ${ }^{8}$ Os mecanismos de ameaça desativam-se e emerge um sentido de contentamento e confiança que faz que cada um de nós se sinta capaz de estar feliz, adaptado às coisas tal e qual como são, sem as lutas e as angústias de quem acredita ter de as mudar. ${ }^{8}$

E o que acontece quando perante uma ameaça chamada COVID-19 o homem se vê precisamente privado destes mecanismos reguladores? Se a ameaça ativa a insegurança, a desconfiança, a desproteção e os medos e perdas mais basilares da existência humana, qual a dimensão do seu impacto perante uma liberdade de escolha condicionada e uma conectividade e afetividade comprometidas? Qual a magnitude do eco da falta de afetividade dentro de cada um de nós? Até onde pode ele chegar? De que modo tudo isto pode levar a que cada um se reequacione e repense o que realmente deseja da sua vida?

Talvez esta experiência dolorosa seja, na sua essência, uma verdadeira porta para cada um descobrir e aceder ao que realmente importa, ao que genuinamente nos equilibra.

\section{MUDANÇAS DE VIDA POSITIVAS E CRESCIMENTO PESSOAL}

"Vou para o trabalho, venho do trabalho, vejo os emails e fico a responder até a fadiga vencer. Durmo poucas horas, o despertador toca, um novo dia começa e, ensonado, lá vou eu outra vez. O meu filho entristecido diz-me que precisa de falar comigo, mas não tenho tempo. "Mais logo falamos", digo-Ihe. "Agora não tenho mesmo tempo". A minha mãe telefona-me e digo-Ihe "logo falo", mas nunca mais me lembro e falo-Ihe dois dias depois.

Fez 50 anos a minha maior amiga e mais uma vez esqueci-me. Nem sei em que dia estou. Como havia de me lembrar?

Afinal que vida é esta? Ando sempre a correr. De facto, trabalho muito e até ganho bem. Mas de que me serve, se não tenho tempo para ouvir o meu filho, se me esqueço de telefonar à minha mãe e dos anos da minha maior amiga. O que me resta disto tudo? Passo pela vida a correr, sem saborear o que mais gosto, a falhar com todos e comigo próprio.

Agora parei à força, aliás paramos todos, o que parecia impossivel aconteceu! Afinal não é preciso tanta correria, 
ganhei menos ou quase nada, é certo, mas senti-me tão melhor. Tive tempo para todos, tive tempo para pensar na minha vida e uma coisa é certa, não quero mais esta pressão, quero mesmo viver. Não vou deixar passar mais esta oportunidade que a vida me dá".

O ser humano é fascinante nas suas capacidades e até nas suas limitações. Desde há séculos que a capacidade de transformar a adversidade numa conquista e crescimento pessoal tem sido alvo do interesse da arte, da filosofia, da espiritualidade e, mais recentemente, da comunidade científica. ${ }^{9}$ Mas, como pode o sofrimento ser catalisador de mudanças de vida positivas e crescimento pessoal? Como poderá uma pandemia e todos os seus efeitos devastadores constituir uma força motriz para algo melhor? Será possível a coexistência do sofrimento e da perturbação com o crescimento e o reequilíbrio? Se sim, como?

A ciência defende que são precisamente as caraterísticas disruptivas do acontecimento (neste caso, a pandemia) que o tornam simultaneamente desencadeador de uma crise e potencialmente desencadeador de processos de crescimento pessoal, dos quais emerge uma nova matriz cognitiva, emocional, comportamental e existencial, capaz de dar um novo sentido ao mundo e às experiências. ${ }^{9-10}$ É precisamente a crise e o sofrimento que provocam um "abalo sísmico" nas estruturas cognitivas que regem o funcionamento psicológico e a compreensão do mundo. ' Introduz-se, assim, uma maior flexibilidade psicológica e uma oportunidade para buscar novas significações para todas as transformações que estão a ser vivenciadas. Neste esforço de lidar com a experiência e de criar um novo referencial, mais complexo e adaptativo, o ser humano encontra muitas vezes, através do sofrimento, resposta para as questões mais importantes da vida $^{10}$ : como quero realmente ser depois de tudo isto?, que tipo e modos de relacionamento quero privilegiar?, que filosofia e estilos de vida quero adotar ora em diante?, qual é o verdadeiro propósito que quero dar à minha vida? É da resposta a estas questões que poderá emergir um novo sentido de identidade e de conectividade consigo, com o outro, com o ambiente e com o mundo.

\section{CONCLUSÃO}

Estes são tempos difíceis, pontuados por mudanças profundas. Mas, apesar de todos os desafios que nos foram colocados e do sofrimento que Ihes está inerente, muitas mudanças positivas puderam e podem despontar no nosso modo de ser e estar, e no modo de lidarmos com os outros e com aquilo que nos circunda. Até o próprio planeta agradece!

\section{RESPONSABILIDADES ÉTICAS}

CONFLITOS DE INTERESSE: Os autores declaram não possuir conflitos de interesse.

SUPORTE FINANCEIRO: O presente trabalho não foi suportado por nenhum subsídio ou bolsa.

PROVENIÊNCIA E REVISÃO POR PARES: Não comissionado; revisão externa por pares.

\section{ETHICAL DISCLOSURES}

CONFLICTS OF INTEREST: The authors have no conflicts of interest to declare.

FINANCING SUPPORT: This work has not received any contribution, grant or scholarship.

PROVENANCE AND PEER REVIEW: Not commissioned; externally peer reviewed.

\section{REFERÊNCIAS}

1. Friston K, Kiebel S. Predictive coding under the free-energy principle. Philos Trans R Soc Lond B Biol Sci. 2009:364:121121. doi:10.1098/rstb.2008.0300.

2. Fiorillo A, Gorwood P. The consequences of the COVID-19 pandemic on mental health and implications for clinical practice. Eur Psychiatry. 2020;63:e32. doi:10.1192/j. eurpsy.2020.35.

3. Pfefferbaum B, North CS. Mental Health and the Covid-19 Pandemic. N Engl J Med. 2020 (in press). doi:10.1056/NEJMp2008017.

4. Rogers JP, Chesney E, Oliver D, Pollak TA, McGuire P, Fusar-Poli P, et al. Psychiatric and neuropsychiatric presentations associated with severe coronavirus infections: a systematic review and meta-analysis with comparison to the COVID-19 pandemic. Lancet Psychiatry. 2020 (in press). doi: 10.1016/ S2215-0366(20)30203-0.

5. Ornell F, Schuch JB, Sordi AO, Kessler FH. "Pandemic fear" and COVID-19: mental health burden and strategies [published correction appears in Braz J Psychiatry. 2020;42:333].Braz J Psychiatry. 2020;42:232-5. doi:10.1590/1516-4446-20200008.

6. Selman L, Burrell A. The effect of funeral practices on bereaved friends and relatives mental health and bereavement: implications for Covid-19. Bethesda: National Institute for Health Research:2020.

7. Wallace CL, Wladkowski SP, Gibson A, White P. Grief During the COVID-19 Pandemic: Considerations for Palliative Care Providers. J Pain Symptom Manage. 2020;60:E70-6. doi: 10.1016/j.jpainsymman.2020.04.012.

8. Choden GP. Mindful Compassion: How the Science of Compassion Can Help You Understand Your Emotions, Live in the Present, and Connect Deeply with Others. Oakland: New Harbinger Publications; 2014.

9. Park C. Overview of Theoretical Perspectives. In: Park C, Lechner S, Antoni M, Stanton A, editors. Medical illness and positive life changes: can crisis lead to personal transformation. Washington: APA; 2009.p.11-30.

10. Tedeschi R, Park C, Calhoum L. Posttraumatic growth: positive changes in the aftermath of crisis. New Jersey: Psychology Press; 1998. 